\title{
Glycerol carbonate methacrylate: a cross-linking agent for hydroxyurethane-acrylate coatings
}

\author{
Roberto MORALES-CERRADA, Bernard BOUTEVIN, Sylvain CAILLOL ${ }^{*}$
}

\begin{abstract}
Poly(meth)acrylates are well-known commodity polymers widely used for coating applications due to easy production, low cost and interesting properties such as their relatively high thermal stability, resistance to breakage and transparency. Some of these properties can be improved by cross-linking, therefore an additional functionalization is necessary. Carbonate group allowed reaction with amines to generate a urethane linkage without the use of toxic and harmful isocyanates. We have synthesized (meth)acrylic copolymers functionalized with cyclic carbonates groups using butyl acrylate (BA), methyl methacrylate (MMA) and glycerol carbonate methacrylate (GCMA) as comonomers to obtain cross-linkable polymers. Different ratios of $\mathrm{BA}$ and MMA have been used in order to evaluate the effect on the thermomechanical properties. The cross-linking was performed with tris(2-aminoethyl)amine at $80^{\circ} \mathrm{C}$ during $2 \mathrm{~h}$ and was quantitative. The cross-linked hydroxyurethane acrylate copolymers were fully characterized and were used as coatings on glass and steel. The ease of the application and curing process as well as the adhesion strength tests showed that these cross-linked copolymers are promising materials as coating on glass and steel.
\end{abstract}

\section{Introduction}

Coatings are a particularly important part of the material industry. Many every day and specific products are coated by different materials depending of their uses or applications. Indeed, coatings have many uses such as protection and safety, corrosion prevention, decorative finishing or surfaces cleanliness. Thus, the improvement of the coating materials, the ease of their application, their adhesion and their cost as well as their manufacturing from renewable and sustainable resources[1] are major issues nowadays. Organic coatings meet many of these characteristics and are therefore widely used in the coating industry today.

Among all the polymers employed for coatings, polyacrylates are quite common for coating applications due to their easy production, low cost and interesting properties such as their relatively high thermal stability and resistance to breakage. Concretely, copolymers of poly(butyl acrylate-co-methyl methacrylate) (P(BA-co-MMA)) are extensively used for adhesives and coatings.[4] In addition, they could bear a large variety of functional groups that allow various cross-linking reactions.[5] For instance, the curing with melamine resins, [6] or the cross-linking reaction of a copolymer of glycidyl methacrylate with amines or carboxylic acids are common techniques for the cross-linking of acrylic resins.[7, 8] Polyurethanes and especially biobased polyurethanes[9] are polymers widely used for coating applications, which 
can improve the coating properties.[10] In addition, the formation of a carbamate linkage by reaction between a hydroxyl-functionalized polyacrylate (e.g. copolymer of 2-hydroxyl acrylate) with diisocyanates is also a technique widely used to obtain cross-linked polyurethane acrylates.[11] However, this method involves the use of isocyanates, which are toxic and probably carcinogenic.[12-15] Furthermore, environmental awareness and new regulations urge industry to seek new reagents, less damaging or harmful for the environment. Among the possibilities to synthesize non-isocyanates polyurethanes (NIPU), which can be used for coatings applications [16], the reaction between cyclic carbonates and amines is one of the most studied. Indeed, this promising route [17-19] could allow interestingly to obtain partially or fully biobased polyhydroxyurethanes.[16, 20-22] Hence, the aminolysis reaction of cyclic carbonates generates hydroxyurethane linkages, more suitable for coatings due to the presence of the hydroxyl functions on the $\beta$-carbon of the urethane moiety. These hydroxyl groups contribute to the formation of additional intramolecular and intermolecular hydrogen bonds that improve the adhesion properties of the material as well as thermal and chemical resistance.[17, 19, 23]

Thus, the functionalization of a radically polymerizable monomer with a cyclic carbonate moiety allows the cross-linking of the resulting polymer with hydroxyurethane bonds.[24] Hence, cyclic carbonate monomers have been studied and commercialized since 1950s, [25-27] however their intensive use in industry has only been developed in the last 15 years.[28] Different synthetic pathways and studies on cyclic carbonate function and its insertion into monomers have been published by various authors and companies.[29-43] Among these monomers, the 2-(oxo-1,3-dioxolan-4-yl) methyl methacrylate or glycerol carbonate methacrylate (also called glycerin carbonate methacrylate or GCMA, Scheme 1 ) is the most studied monomer for the synthesis of cyclic carbonate functionalized polymers.[44]<smiles>C=C(C)C(=O)OCC1COC(=O)O1</smiles>

Scheme 1. Structure of glycerol carbonate methacrylate (GCMA).

The high reactivity of cyclic carbonate methacrylate monomers was reported for both photo[45-49] and thermal radical polymerizations.[44, 50-52]. Camara et al.[44] studied the radical copolymerization of this monomer and demonstrated that the carbonate group activates the double bond of the methacrylic function. Thus, the polymerization of GCMA was 1.7 times faster than the one of the methyl methacrylate (MMA). In addition, they noted that homopolymerization could lead to gelation, depending on the monomer concentration and the solvent used. Indeed, they reported DMSO as the best solvent for this monomer since gelation was not observed until a concentration of $3 \mathrm{~mol} \cdot \mathrm{L}^{-1}$, contrary to toluene, acetonitrile or methyl ethyl ketone where the gelation occurred at lower concentrations. The gelation was attributed to the hydrogen transfer reaction from the cyclic carbonate to the methacrylic radical, allowing the combination of the cyclic carbonate radical with another methacrylic radical and then the cross-linking. This explanation was first proposed by Brosse et al.[53] and then confirmed by subsequent studies.[44, 52]

Moreover, the reactivity of the aminolysis reaction of cyclic carbonate [54] depends on various factors such as the structure and substituents of both amine $[55,56]$ and cyclic carbonate,[57, $58]$ the molar ratio, $[59,60]$ the solvent $[54,58]$ and the temperature of reaction. $[21,22]$ Thus, 
for the aminolysis reaction of copolymers of GCMA, the choice of the amine is a key factor to allow a high reactivity at mild temperature in a short period of time. Due to the presence of a nitrogen in beta position to the primary amine, tris-(2-aminoethyl)amine (TAEA) has been reported very reactive toward cyclic carbonate group, leading to highly cross-linked thermosets. [24, 61-70]

Even if the copolymerization of GCMA in acrylate copolymers has already been studied,[44] neither the aminolysis reaction nor the use as cross-linker agent have been. Hence, we report for the first-time copolymers of butyl acrylate (BA) and methyl methacrylate (MMA) with glycerol carbonate methacrylate (GCMA) and their cross-linking with TAEA to yield hybrid hydroxyurethane-acrylate thermosets. The coating adhesion and hardness of theses copolymers were studied with the aim of using them for coatings applications.

\section{Materials and methods}

\subsection{Materials}

Butyl acrylate (BA, Sigma-Aldrich, $\geq 99 \%$ ), methyl methacrylate (MMA, Sigma-Aldrich, 99\%), glycerol carbonate methacrylate (GCMA, Specific Polymers), 2,2'-azobis(2-methylpropionitrile) (AIBN, Fluka Analytical, $\geq 98 \%$ ), tris(2-aminoethyl)amine (TAEA, Sigma-Aldrich, 96\%), dimethyl sulfoxide (DMSO, VWR Chemicals, Analytical reagent), methanol (MeOH, VWR Chemicals, AnalR NORMAPUR), methyl ethyl ketone (MEK, Acros Organics, ACS Reagent), deuterated dimethyl sulfoxide (DMSO- $d_{6}, 99.5 \% \mathrm{D}$, Euriso-top) and deuterated chloroform ( $\mathrm{CDCl}_{3}, 99.5 \%$ $D$, Euriso-top) were used as received.

\subsection{Nuclear magnetic resonance (NMR)}

Nuclear magnetic resonance (NMR) spectra were recorded on a Bruker Avance ${ }^{\mathrm{TM}}$ III $400 \mathrm{MHz}$ spectrometer. The instrumental parameters for recording ${ }^{1} \mathrm{H}$ NMR spectra were as follows: flip angle $30^{\circ}$, acquisition time $4 \mathrm{~s}$, pulse delay $1 \mathrm{~s}$, number of scans 16 , and a pulse width of 3.08 us.

\subsection{Fourier transform infrared (FTIR)}

Fourier transform infrared (FTIR) spectra were recorded by attenuated total reflection (ATR) in transmission mode with a ThermoFisher Nicolet 210 FT-IR spectrometer. Spectra were recorded between 4000 and $750 \mathrm{~cm}^{-1}$ with a spectrum resolution of $4 \mathrm{~cm}^{-1}$. All spectra were averaged over 32 scans. The characteristic IR absorption bands are reported in $\mathrm{cm}^{-1}$.

\subsection{Size-exclusion chromatography (SEC)}

The apparent number average molar masses and dispersities $(\Theta)$ of the synthesized polymers were determined by size-exclusion chromatography (SEC) using a triple-detection SEC from Agilent Technologies with its corresponding Agilent software. The system used two PL11136300 ResiPore $300 \times 7.5 \mathrm{~mm}$ columns with THF the eluent with a flow rate of $0.8 \mathrm{~mL} \mathrm{~min}^{-1}$. The detector suite was composed of a PL0390-0605390 LC light scattering detector with two diffusion angles ( $15^{\circ}$ and $90^{\circ}$ ), a PL0390-06034 capillary viscometer, and a 390-LC PL0390-0601 refractive index detector. The number average molar masses and the dispersity were calculated from the refractive index. The entire SEC-HPLC system was thermostated at $35^{\circ} \mathrm{C}$. PMMA standards were used for calibration. Typical sample concentration was $10 \mathrm{mg} \mathrm{mL}^{-1}$.

2.5. Thermogravimetric analyses (TGA) 
Thermogravimetric analyses (TGA) of the purified and dried copolymers samples were performed under nitrogen using a TGA 51 apparatus from TA Instruments. Approximately 10 $\mathrm{mg}$ of sample was placed in an aluminum crucible and heated from room temperature to 500 ${ }^{\circ} \mathrm{C}$ under nitrogen atmosphere $\left(60 \mathrm{~mL} \cdot \mathrm{min}^{-1}\right)$.

\subsection{Differential scanning calorimetry (DSC)}

Differential scanning calorimetry (DSC) analyses were carried out using a NETZSCH DSC200F3 calorimeter. Constant calibration was performed using indium, n-octadecane and n-octane standards. Nitrogen was used as the purge gas $\left(40 \mathrm{~mL} \cdot \mathrm{min}^{-1}\right)$. Approximately $10 \mathrm{mg}$ of sample was placed in pierced aluminum pans and the thermal properties were recorded between - 150 ${ }^{\circ} \mathrm{C}$ and $150{ }^{\circ} \mathrm{C}$ at $20^{\circ} \mathrm{C} \cdot \mathrm{min}^{-1}$ to observe the glass transition temperature. The glass transition temperatures $\left(\mathrm{T}_{\mathrm{g}}\right)$ were calculated from the second heating run. All the reported temperatures are middle values.

\subsection{Dynamic Mechanical Analyses (DMA)}

Dynamic Mechanical Analyses (DMA) were carried out on Metravib DMA 25 with Dynatest 6.83 software. Uniaxial stretching of samples was performed while heating at a rate of 3 ${ }^{\circ} \mathrm{C} \cdot \mathrm{min}^{-1}$ from $-110^{\circ} \mathrm{C}$ to $150{ }^{\circ} \mathrm{C}$, keeping frequency at $1 \mathrm{~Hz}$ with a fixed strain $\left(10^{-5} \mathrm{~m}\right)$.

2.8. Synthesis of poly(butyl acrylate-co-methyl methacrylate-co-glycerol carbonate methacrylate) (P(BA-co-MMA-co-GCMA))

As a representative example, in a $250 \mathrm{~mL}$ round-bottomed flask, $3.980 \mathrm{~g}$ of $\mathrm{BA}(31.05 \mathrm{mmol})$, $3.110 \mathrm{~g}$ of MMA (31.06 mmol), $1.464 \mathrm{~g}$ of GCMA (7.86 mmol), and $397 \mathrm{mg}$ of AIBN (2.42 mmol) were dissolved in $70 \mathrm{~mL}$ of DMSO. On the other hand, in a $25 \mathrm{~mL}$ round-bottomed flask, 1.454 $\mathrm{g}$ of GCMA $(7.81 \mathrm{mmol})$ were dissolved in $5 \mathrm{~mL}$ of DMSO. Both solutions were purged by nitrogen bubbling for $20 \mathrm{~min}$. Then the first solution was heated-up to $70{ }^{\circ} \mathrm{C}$, and the second solution was introduced in a syringe and it was added dropwise with a syringe driver $(0.8$ $\mathrm{mL} / \mathrm{h}$ ). The solution was kept with magnetic stirring at $70{ }^{\circ} \mathrm{C}$ for $16 \mathrm{~h}$. Then, resulting copolymer was precipitated by slow addition in $800 \mathrm{~mL}$ of cold methanol at $0{ }^{\circ} \mathrm{C}$. The copolymer was dried in a vacuum oven for $24 \mathrm{~h}$ under vacuum at $70^{\circ} \mathrm{C}$, obtaining $6.671 \mathrm{~g}$ of $\mathrm{P}$ (BA-co-MMA-co-GCMA). Yield was calculated with the obtained mass of the precipitated polymer divided by the total mass of the reagents (yield $=64 \%$ ). The resulting polymer was analyzed by ${ }^{1} \mathrm{H}$ NMR in DMSO- $d_{6}$, SEC in THF, TGA, and DSC.

\subsection{Synthesis of $P(B A-c o-M M A)$}

In a $100 \mathrm{~mL}$ round-bottomed flask, $2.804 \mathrm{~g}$ of BA (21.88 mmol), $2.196 \mathrm{~g}$ of MMA (21.93 mmol) and $200 \mathrm{mg}$ of AIBN (1.22 mmol) were dissolved in $43 \mathrm{~mL}$ of DMSO. The solution was purged by nitrogen bubbling for $20 \mathrm{~min}$. Then it was heated-up to $70^{\circ} \mathrm{C}$ and it was kept with magnetic stirring at $70{ }^{\circ} \mathrm{C}$ for $16 \mathrm{~h}$. Then, resulting copolymer was precipitated by slow addition in 450 $\mathrm{mL}$ of cold methanol at $0{ }^{\circ} \mathrm{C}$. The copolymer was dried in a vacuum oven for $24 \mathrm{~h}$ under vacuum at $70{ }^{\circ} \mathrm{C}$, obtaining $2.110 \mathrm{~g}$ of $\mathrm{P}(\mathrm{BA}-\mathrm{Co}-\mathrm{MMA})$. Yield was calculated with the obtained mass of the precipitated polymer divided by the total mass of the reagents (yield $=41 \%$ ). The resulting polymer was analyzed by ${ }^{1} \mathrm{H}$ NMR in DMSO- $d_{6}$, FTIR, SEC, TGA, and DSC.

\subsection{Cross-linking of P(BA-co-MMA-co-GCMA) with TAEA}

As a representative example, $500 \mathrm{mg}$ of $\mathrm{P}$ (BA-co-MMA-co-GCMA) ([BA]:[MMA]:[GCMA] = 44:38:18) were dissolved in $0.5 \mathrm{~mL}$ of MEK in a hemolysis tube. Then, $128 \mathrm{mg}(0.84 \mathrm{mmol})$ of 
TAEA were added and the viscous solution was mixed with a vortex mixer. Then the solution is quickly transferred to a rectangular aluminum pan, which it was introduce to the oven at $80^{\circ} \mathrm{C}$ for $2 \mathrm{~h}$. The resulting materials were analyzed by FTIR, TGA, DSC and DMA.

\subsection{Swelling index}

Three samples of around $30 \mathrm{mg}$ each, were separately put in THF for $24 \mathrm{~h}$. The swelling index (SI) was calculated using the Equation 1 where $m_{1}$ is the mass of the material after swelling in THF and $m_{2}$ is the initial mass of the material.

$S I(\%)=\frac{m_{1}-m_{2}}{m_{2}} \times 100$

\subsection{Gel content}

After SI measurements, the three samples were dried in a ventilated oven at $70{ }^{\circ} \mathrm{C}$ for $24 \mathrm{~h}$. The gel content (GC) was calculated using the Equation 2, where $m_{3}$ is the mass of the material after the oven and $m_{2}$ is the initial mass of the material.

$G C(\%)=\frac{m_{3}}{m_{2}} \times 100$

\subsection{Film application}

As a representative example of a cross-linked film application in a surface, $500 \mathrm{mg}$ of $\mathrm{P}$ (BA-coMMA-co-GCMA) [38:44:18]) were dissolved in $0.5 \mathrm{~mL}$ of MEK in a hemolysis tube and it was mixed with a vortex. Then, $107 \mathrm{mg}(0.70 \mathrm{mmol})$ of TAEA were added and the viscous solution was mixed with a vortex mixer. The film was quickly applied in the chosen surface (steel or glass) with a TQC VF2147 baker film applicator (width $60 \mathrm{~mm}$, gap $200 \mu \mathrm{m}$ ) pushed by a TQC Sheen Automatic Film Applicator $1133 \mathrm{~N}$ film applicator. The solvent was evaporated at room temperature for $1 \mathrm{~h}$ and the films were introduced in an oven at $80^{\circ} \mathrm{C}$ for $2 \mathrm{~h}$. The thickness of the films was measured for films applied in a polytetrafluoroethylene (PTFE) sheet by the same method, which can be easily detached and measured using a caliper $(150 \pm 50 \mu \mathrm{m})$.

\subsection{Adhesion strength}

The adhesion property of four different films (P(BA-co-MMA-co-GCMA) [47:35:18] and P(BAco-MMA-co-GCMA) [38:44:18], cured and uncured for both copolymers) on steel and glass was characterized using the ASTM D3359 standard test method (tape test) using a TQC CC2000 cross cute adhesion test kit. In this method, two series of properly spaced and parallel incisions are drawn with a crosshatch cutter on coating casted on steel and glass plates to obtain a pattern of 25 squares. After the tape has been applied and pulled off with a standard scotch, the cut area is then inspected and rated according to the percentage of the square remaining on the test panel. There are six levels of adhesion performance from 0 to 5, 0 corresponding to an extremely poor adhesion performance and 5 corresponding to an excellent adhesion performance.

\section{Results and discussion}

3.1. Synthesis and characterization of $\mathrm{P}(\mathrm{BA}-\mathrm{co}-\mathrm{MMA}-\mathrm{co}-\mathrm{GCMA})$ 
Copolymerization of BA, MMA and GCMA was performed in DMSO for $16 \mathrm{~h}$ at $70^{\circ} \mathrm{C}$ using AIBN as initiator (Scheme 2). Three BA/MMA/GCMA copolymers were synthesized with different BA and MMA ratios but with the same GCMA ratio (Table 1, entries 1 to 3 ). The use of different BA and MMA ratios allowed to modulate some properties of the resulting copolymers such as the glass transition temperature $\left(\mathrm{T}_{\mathrm{g}}\right)$. Additionally, a BA/MMA copolymer (without GCMA) was also synthesized in order to compare the influence of the GCMA in the copolymer properties (Table 1 , entry 4). More details about the reaction can be found in the Appendix A (supplementary data) section 1.

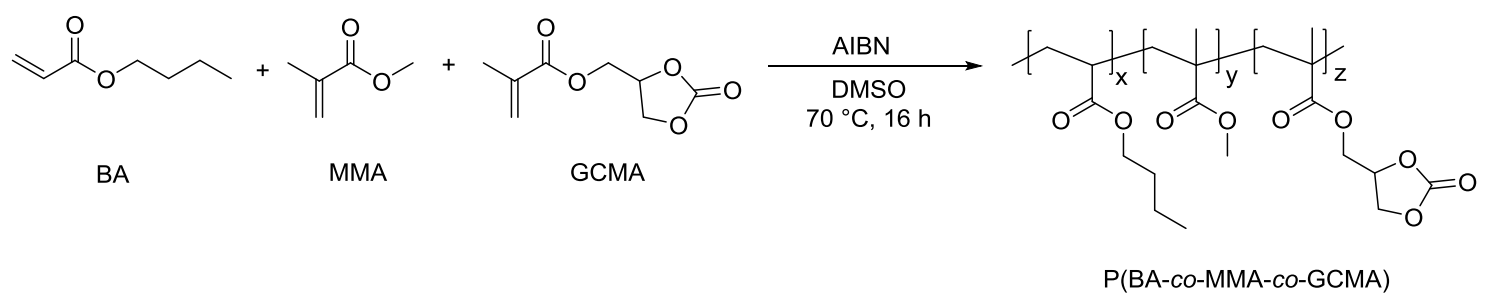

Scheme 2. Copolymerization of BA, MMA and GCMA.

Table 1. Results obtained for BA, MMA and GCMA copolymerization.

\begin{tabular}{|l|c|c|c|c|c|}
\hline Entry & $\begin{array}{c}{[\mathrm{BA}]:[\mathrm{MMA}]:[\mathrm{GCMA}]} \\
\text { initial monomer ratio }\end{array}$ & $\begin{array}{c}{[\mathrm{BA}]:[\mathrm{MMA}]:[\mathrm{GCMA}]} \\
\text { copolymer ratio }^{\mathrm{a}}\end{array}$ & $\begin{array}{c}\text { Yield } \\
(\%)^{\mathrm{b}}\end{array}$ & $\mathrm{Mn}^{\left.\mathrm{g} \cdot \mathrm{mol}^{-1}\right)}$ & Đ \\
\hline 1 & $50: 30: 20$ & $47: 35: 18$ & 59 & 17,500 & 3.9 \\
\hline 2 & $40: 40: 20$ & $38: 44: 18$ & 64 & 16,500 & 3.1 \\
\hline 3 & $30: 50: 20$ & $31: 51: 18$ & 58 & 18,300 & 3.6 \\
\hline 4 & $50: 50: 0$ & $45: 55: 0$ & 41 & 33,000 & 1.5 \\
\hline
\end{tabular}

${ }^{a}$ Calculated by integration of ${ }^{1} \mathrm{H}$ NMR spectrum of the precipitated polymer.

${ }^{b}$ Calculated by weight of the precipitated polymer.

Yields of the resulting copolymers displayed in Table 1 were calculated with the weights of the precipitated copolymers and the sum of all the introduced monomers and initiator for each entry. Despite fair yields, ${ }^{1} \mathrm{H}$ NMR spectra of the crude reactions after $16 \mathrm{~h}$ showed that almost all the monomers have reacted (Figure A1). The low intensity of the signals corresponding to the unsaturation of the monomers did not allow to integrate them accurately, but a conversion $\geq 95 \%$ of all the monomers can be considered for each entry. The difference between yield and conversion may be explained by the formation of low molar masses chains, removed by precipitation in cold methanol.

The presence of the three monomers in the resulting copolymers was confirmed by ${ }^{1} \mathrm{H}$ NMR spectra of the precipitated polymers of entries 1 to 3 (Figure $1, A 2$, and $A 3$ ). The precipitated polymers showed all the expected signals of the P(BA-co-MMA-co-GCMA). The assignment of these signals have been carried out with the already reported values of the BA/MMA copolymers[71] and the GCMA copolymer.[44] The peaks centered at 3.55 and $3.95 \mathrm{ppm}$ correspond to the $-\mathrm{OCH}_{3}$ from the MMA (g) and to the $-\mathrm{OCH}_{2}$ - from BA (c), respectively. Additionally, the ${ }^{1} \mathrm{H}$ NMR spectra exhibit the characteristic signals from the cyclic carbonate moiety between 4.10 and $5.10 \mathrm{ppm}$, confirming the insertion of the GCMA in the copolymer. The ${ }^{1} \mathrm{H}$ NMR spectrum of the BA and MMA copolymer also shows the presence of the expected signal for this copolymer (Figure A4). 


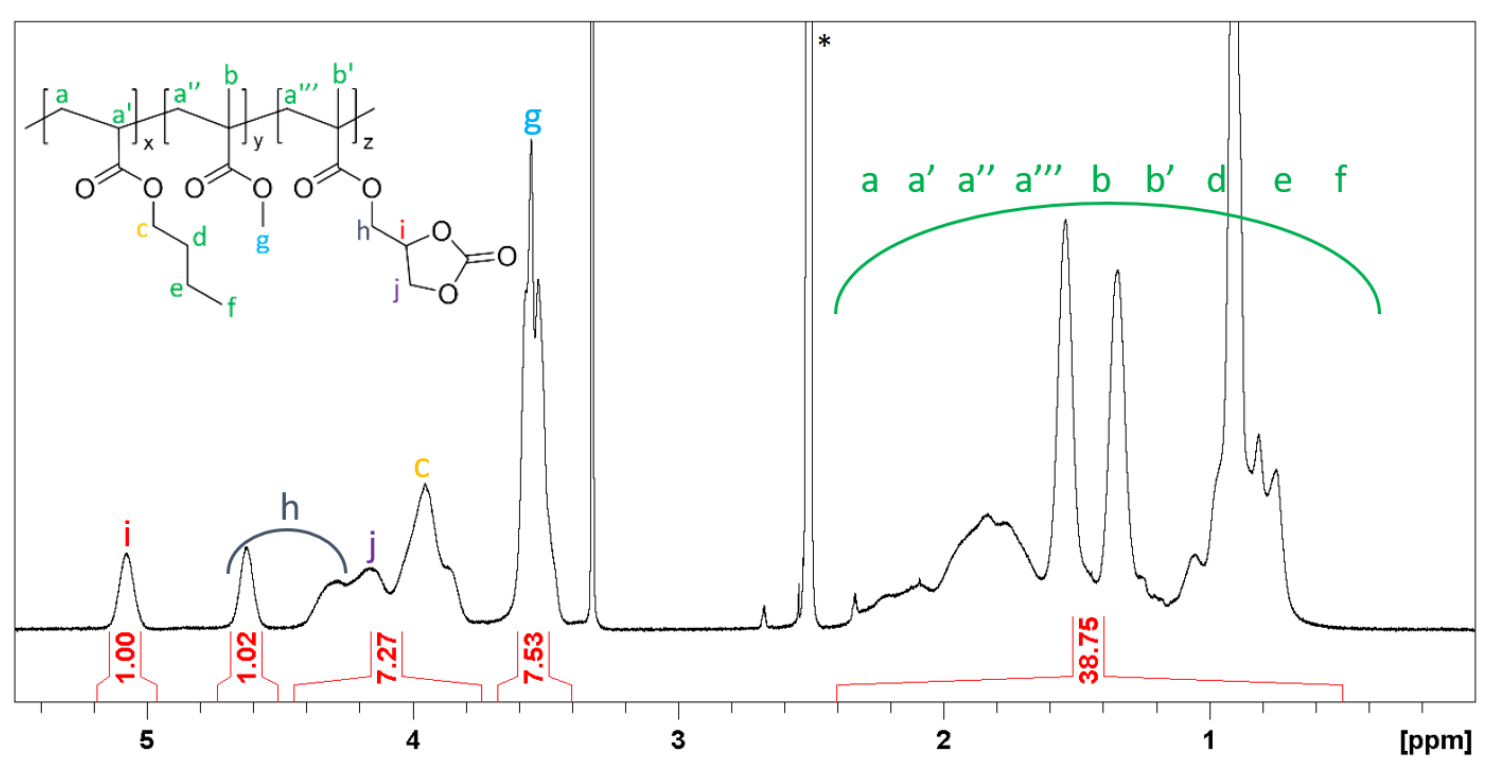

Figure 1. ${ }^{1} \mathrm{H}$ NMR spectrum (400 MHz, DMSO- $d_{6}$ ) of entry 2 (P(BA-co-MMA-co-GCMA) [38:44:18]). The starred resonance is due to the solvent.

The composition of each copolymer was determined using the integration values of the corresponding signals in ${ }^{1} \mathrm{H}$ NMR spectra of the precipitated polymers by equations 3,4 and 5 .

$$
\begin{aligned}
& \% B A=\frac{\left(I_{h^{\prime}+j+c}-I_{h^{\prime}}-I_{j}\right) / 2}{\frac{I_{i}}{1}+\frac{I^{\prime}+j+c^{-I} h^{\prime-I} j}{2}+\frac{I_{g}}{3}} \\
& \% M M A=\frac{I_{g} / 3}{\frac{I_{i}}{1}+\frac{I^{\prime}+j+c^{-I} h^{\prime-I} j}{2}+\frac{I_{g}}{3}} \\
& \% G C M A=\frac{I_{i} / 1}{\frac{I_{i}}{1}+\frac{{ }^{I}+j+c^{\prime} h^{\prime-I}}{2}+\frac{I_{g}}{3}}
\end{aligned}
$$

The copolymer compositions obtained by ${ }^{1} \mathrm{H}$ NMR (Table 1 ) indicated that the monomer ratios in the precipitated copolymers are close to the expected ones. Nevertheless, copolymers of entries 1 to 3 possess a slightly higher MMA ratio than expected, whereas the BA and GCMA ones are lower. Moreover, entry 4 showed the same behavior between BA and MMA ratios. This phenomenon may be explained by the reactivity ratios of $B A$ and MMA copolymerization $\left(r_{\mathrm{BA}} \approx 0.3\right.$ and $\left.\mathrm{r}_{\mathrm{MMA}} \approx 2.0\right)$.[72, 73] Both $\mathrm{BA}$ and MMA radicals react preferably with a MMA monomer rather than $B A$ monomer. Therefore, all the generated radicals in the copolymerization of BA, MMA and GCMA react preferably first with a GCMA, then with a MMA and finally with a BA monomer. However, GCMA ratio is also slightly lower than expected in all the copolymers (entries 1 to 3). This is probably due to the slow addition of this monomer during the polymerization, maintaining a low concentration.

FTIR spectra of entries 1 to 4 are superimposed in Figure 2 and confirmed the presence of GCMA in the polymer chains. The spectra of entries 1 to 3 show two strong bands at $\tilde{v} \approx 1750$ and $1800 \mathrm{~cm}^{-1}$ corresponding to the carbonyl groups of the esters of both BA, MMA and GCMA 
and to the carbonyl group of the cyclic carbonate, respectively. Entry 4, which corresponds to the copolymer of BA/MMA, does not show any signal at $\tilde{v}=1800 \mathrm{~cm}^{-1}$ as expected. The strong bands present in all the entries between $\tilde{v}=1000$ and $\tilde{v}=1250 \mathrm{~cm}^{-1}$ can be attributed to the C$\mathrm{O}$ stretching from the esters. The peaks present between $\tilde{v}=2800$ and $\tilde{v}=3100 \mathrm{~cm}^{-1}$ are due to the $\mathrm{C}-\mathrm{H}$ stretching of the alkyl chains.

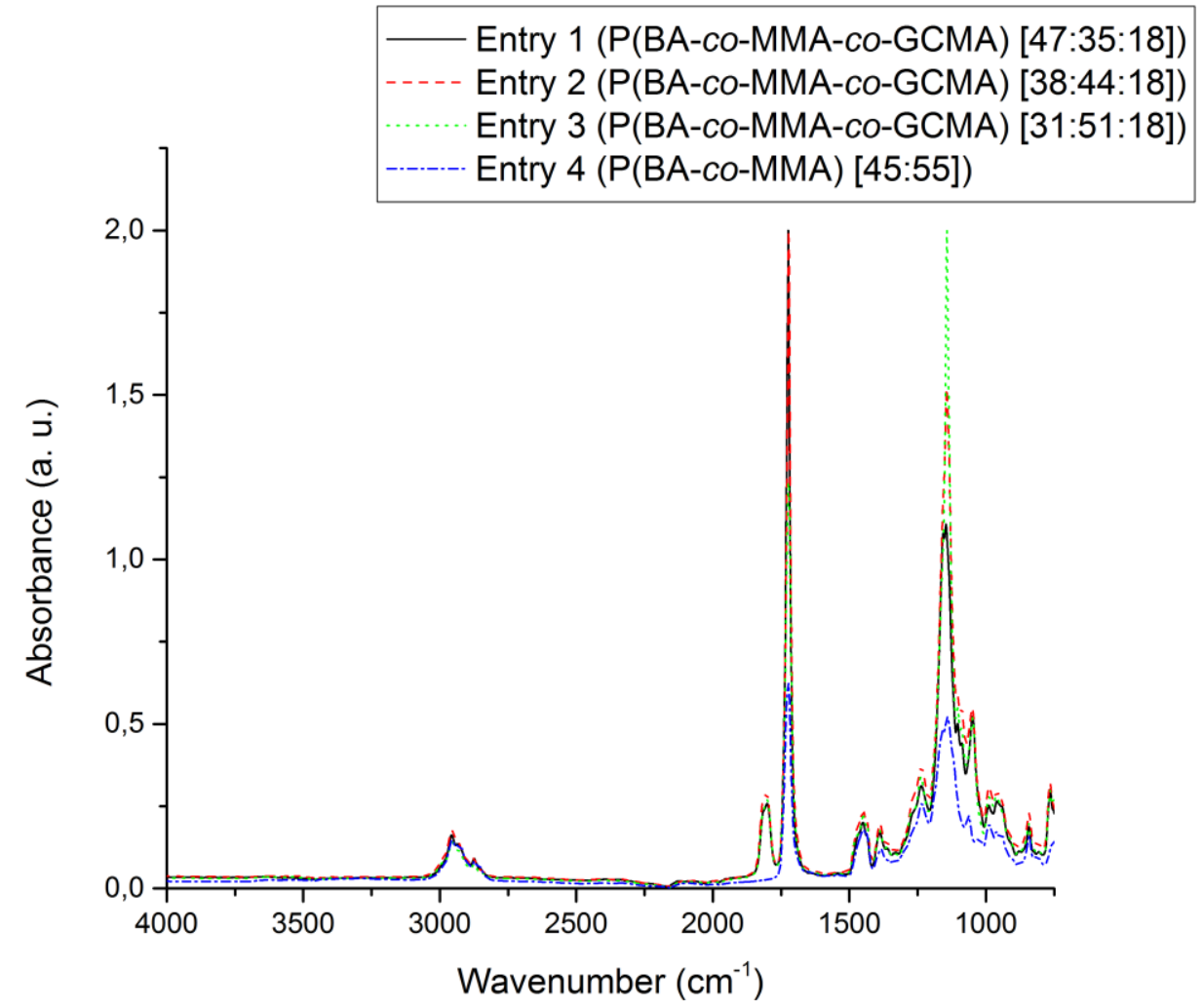

Figure 2. FTIR spectra (ATR) of entry 1 (P(BA-co-MMA-co-GCMA) [47:35:18]), entry 2 (P(BA-co-MMA-co-GCMA) [38:44:18]), entry 3 (P(BA-co-MMA-co-GCMA) [31:51:18]) and entry 4 (P(BA-co-MMA) [45:55]). 
The size exclusion chromatograms of entries 1 to 4 are presented in Figure 3, and number average molar masses and dispersities of the obtained copolymers are shown in Table 1. Entries 1 to 3 exhibit one main population centered between 13.5 to $14.5 \mathrm{~min}$, and a second small population centered around $17 \mathrm{~min}$, which is less visible but also present in the case of entry 1. Thus, GCMA induced the formation of a second population composed of smaller molar masses chains which are not removed by precipitation, resulting in an increase of the dispersity. Concerning the entry 4 , the dispersity was lower than for the copolymers containing GCMA since only one population was observed.

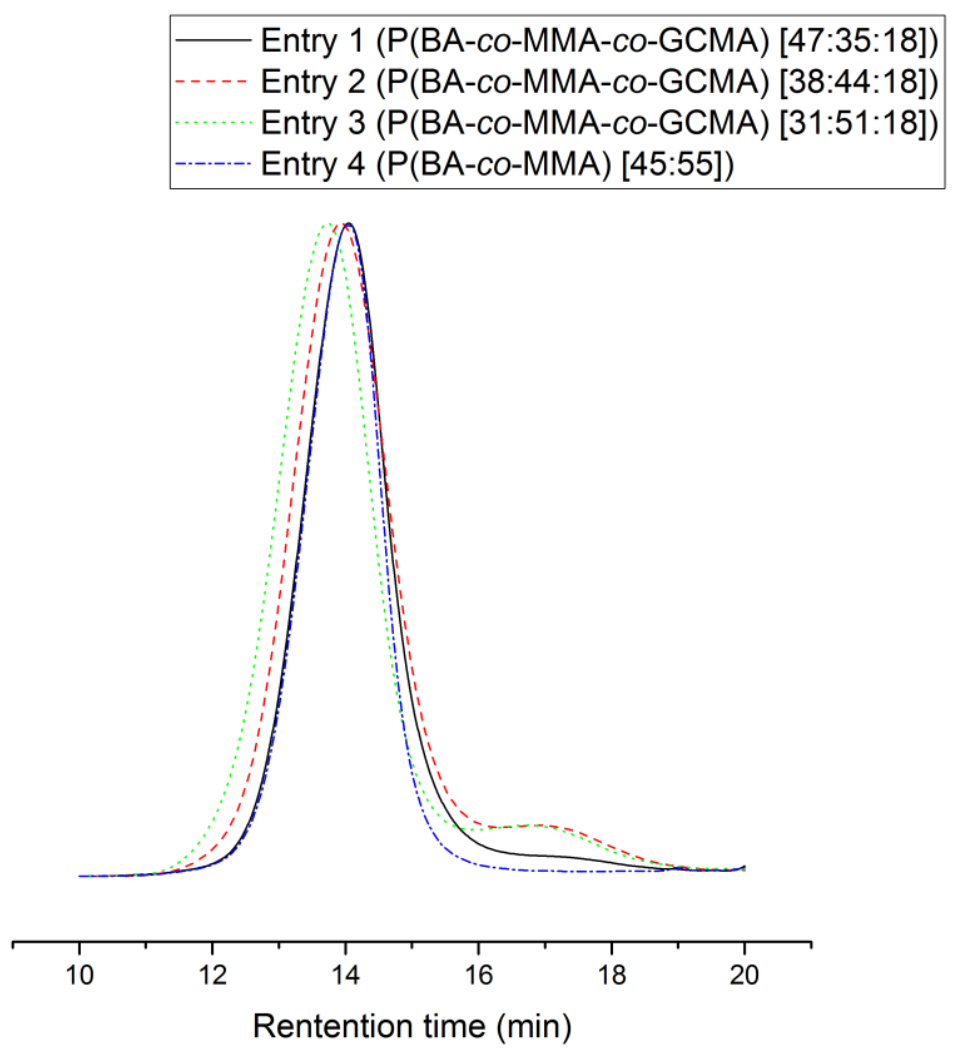

Figure 3. SEC chromatograms of entry 1 ( $\mathrm{P}(\mathrm{BA}-\mathrm{-CO}-\mathrm{MMA}-\mathrm{co}-\mathrm{GCMA})$ [47:35:18]), entry 2 (P(BA-co-MMA-co-GCMA) [38:44:18]), entry 3 (P(BA-co-MMA-co-GCMA) [31:51:18]) and entry 4 (P(BA-co-MMA) [45:55]).

Thermogravimetric analyses (TGA) of entries 1 to 4 are presented in Figures A8 and the results are summarized in Table 2 . All the copolymers synthesized in this work showed a relatively good thermal stability since the $5 \%$ of weight loss temperatures was close to $300{ }^{\circ} \mathrm{C}$. However, this temperature increased slightly with the BA ratio (entries 1 to 3 ), as already reported by Kumar Konaganti et al.,[74] which observed that thermal stability of the BA and MMA copolymers increased with the mole percentage of BA in the copolymer. They concluded that this difference was observed because of the different degradation mechanism depending on the BA and MMA ratio (one-step or two-step process). The comparison of these values with the value obtained for entry 4 suggests that the introduction of GCMA monomer in the copolymer do not significantly change the thermal stability of the copolymer. On the other hand, the DSC thermograms, displayed in Figure 5, A10, A11 and A12 and which results are recapped in Table 2 , indicated that higher ratios of $B A$ in the polymer chain decreased the glass transition temperatures $\left(T_{g}\right)$ as expected.[75] The presence of the GCMA seems to increase the $T_{g}$ value of resulting copolymer compare to a BA/MMA copolymer, which was in good agreement with the previously reported results.[75] This can be easily observed comparing the $T_{g}$ of entry 2 
and 4: both entries have a similar BA and MMA relative ratios, and the observed $\mathrm{T}_{\mathrm{g}}$ for entry 2 is $29^{\circ} \mathrm{C}$ higher than $\mathrm{T}_{\mathrm{g}}$ of entry 4, which does not contain GCMA monomer. This behavior is also expected since the $T_{g}$ of the GCMA homopolymer is higher than both homopoly(BA) and homopoly(MMA).[44]

Table 2. Results of thermogravimetric analyses and differential scanning calorimetry of entries 1 to 4 .

\begin{tabular}{|l|c|c|c|c|}
\hline Entry & {$[\mathrm{BA}]:[\mathrm{MMA}]:[\mathrm{GCMA}]$} & $\mathrm{T}_{\mathrm{d} 5 \%}\left({ }^{\circ} \mathrm{C}\right)$ & Char yield $^{\mathrm{a}}(\%)$ & $\mathrm{T}_{\mathrm{g}}\left({ }^{\circ} \mathrm{C}\right)$ \\
\hline 1 & $47: 35: 18$ & 314 & 3.1 & 31 \\
\hline 2 & $38: 44: 18$ & 294 & 1.1 & 44 \\
\hline 3 & $31: 51: 18$ & 289 & 2.2 & 59 \\
\hline 4 & $45: 55: 0$ & 304 & 3.2 & 15 \\
\hline
\end{tabular}

${ }^{\text {a }}$ Determined at $500{ }^{\circ} \mathrm{C}$

\subsection{Cross-linking of $P(B A-c o-M M A-c o-G C M A)$ with TAEA}

The three copolymers containing GCMA (entries 1 to 3 ) were cured by the aminolysis reaction of the cyclic carbonate group with tris(2-aminoethyl)amine (TAEA), leading to the cross-linked copolymers by hydroxyurethane linkages (entries 5 to 7, respectively), as depicted in Scheme 3. Methyl ethyl ketone (MEK) was chosen as solvent since it is a suitable solvent for the copolymers and is widely used as solvent in the industry. For each copolymer, one equivalent of TAEA for each equivalent of GCMA was added, which was calculated from the percentage of cyclic carbonate in the copolymer obtained by ${ }^{1} \mathrm{H}$ NMR. Once the corresponding amount of TAEA was added, the viscosity of the solution increased rapidly, suggesting that the reaction occurred at room temperature. The color of the viscous copolymer solution, initially colorless to slightly white, turned to yellow after the addition of TAEA, and then to light brownish yellow after $2 \mathrm{~h}$ at $80^{\circ} \mathrm{C}$.

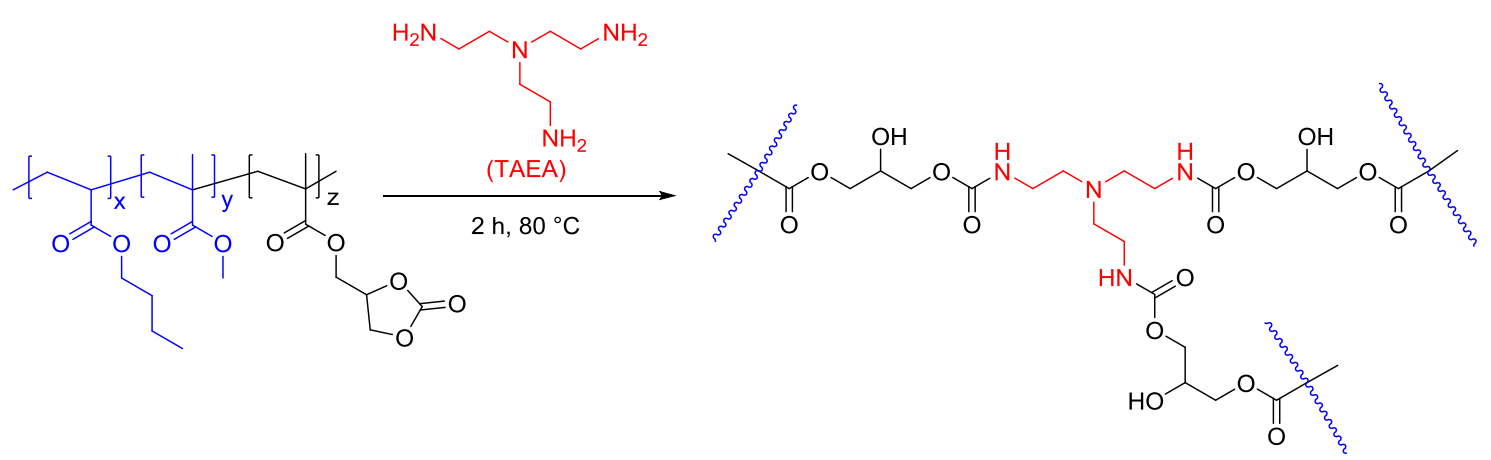

Scheme 3. Cross-linking reaction of $P(B A-c o-M M A-c o-G C M A)$ with TAEA.

FTIR spectroscopy is a useful tool to check the efficiency of the cross-linking reaction of these copolymers. FTIR spectra of entries 5 to 7 , superimposed with their respective uncross-linked copolymers are displayed in figures A5, 4 and A6, respectively. As described above, the cyclic carbonate function produces a band at $\tilde{v} \approx 1800 \mathrm{~cm}^{-1}$ which is clearly separated of the strong 
carbonyl peak generated from the carbonyl of esters groups $\left(\tilde{v} \approx 1720 \mathrm{~cm}^{-1}\right)$. Thus, even if we are not able to quantify the remaining cyclic carbonate in the polymer, we can conclude that the cross-linked reaction yields for all the copolymers containing GCMA were quantitative since the cyclic carbonyl band was not visible after curing reaction with TAEA. Additionally, the presence of the urethane moieties was evidenced by two overlapped wide bands centered at $\tilde{v}$ $\approx 3350 \mathrm{~cm}^{-1}$, corresponding to $\mathrm{N}-\mathrm{H}$ and $\mathrm{O}-\mathrm{H}$ stretching of the hydroxyurethane bond, as well as a shoulder at $\tilde{v} \approx 1670 \mathrm{~cm}^{-1}$ which can be attributed to the $\mathrm{C}=0$ stretching of the urethane linkage.

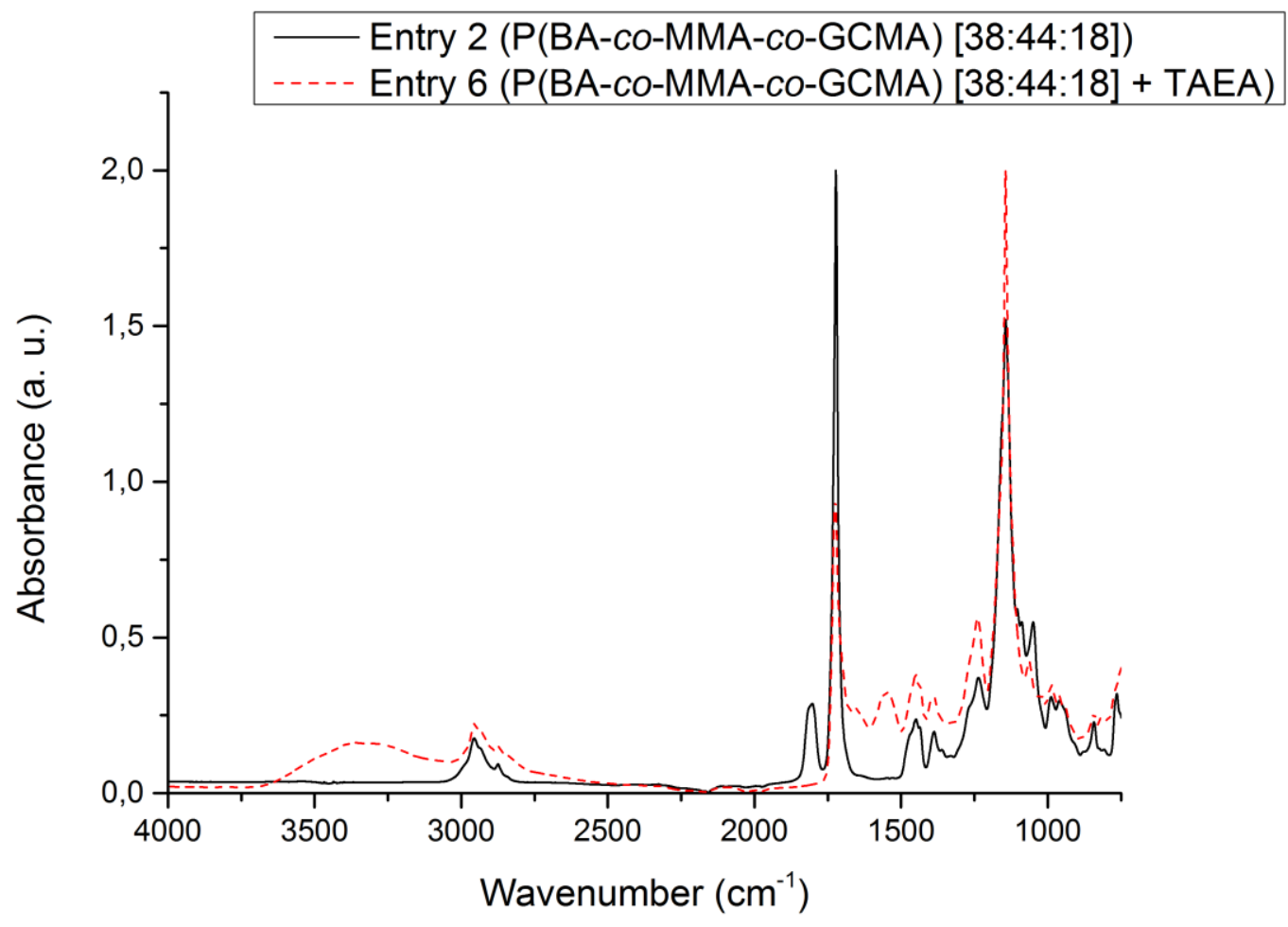

Figure 4. FTIR spectra (ATR) of entry 2 (P(BA-co-MMA-co-GCMA) [38:44:18]) and entry 6 (P(BA-co-MMA-co-GCMA) [38:44:18] + TAEA).

TGA analyses showed a strong decrease of the $5 \%$ weight loss temperature compare to the uncured copolymers as shown in Table 3 and Figure A9. This is probably due to the decomposition of the urethane linkage, which starts to revert from $160{ }^{\circ} \mathrm{C}$. Above $250{ }^{\circ} \mathrm{C}$, urethane linkage starts to decompose, yielding free isocyanates, alcohols, free amines, olefins and carbon dioxide.[76]Moreover, the reversibility of the hydroxyurethane linkage formed by TAEA is even easier compare to other amines and may occur at relatively low temperatures.[77, 78] Additionally, a small amount of unreacted TAEA may be present in the material. On the other hand, the cross-linked copolymers with higher BA ratios exhibited higher $5 \%$ weight loss temperature values, following the same behavior that the uncured copolymers and previously observed by Kumar Konaganti et al.[74] for BA/MMA copolymers. Additionally, cross-linked copolymers exhibited higher char yields than uncross-linked ones because of their higher number of covalent bonds in the material, especially for entry 7 , in which the char yield value reached $11 \%$ (vs $2.2 \%$ for entry 3 ).

DSC thermograms of the cured copolymers are displayed in Figures 5, A10 and A11 and their results are summarized in Table 3 . All the cured copolymers exhibited similar glass transition 
temperature values (around $35{ }^{\circ} \mathrm{C}$ ) contrary to their uncured precursors. Thus, the BA/MMA relative ratio does not affect significantly the $T_{g}$ values after the curing process. Usually, the $T_{g}$ values of cross-linked (co)polymers should be higher than their respective uncross-linked ones. However, in this case, we observed that the $\mathrm{T}_{\mathrm{g}}$ did not increase significantly or even decreased compared to the respective uncured copolymers. This is probably due to the presence of a small amount of dangling chain of non-fully reacted TAEA in the material, which can affect considerably to the $T_{\mathrm{g}}$ value of the material.

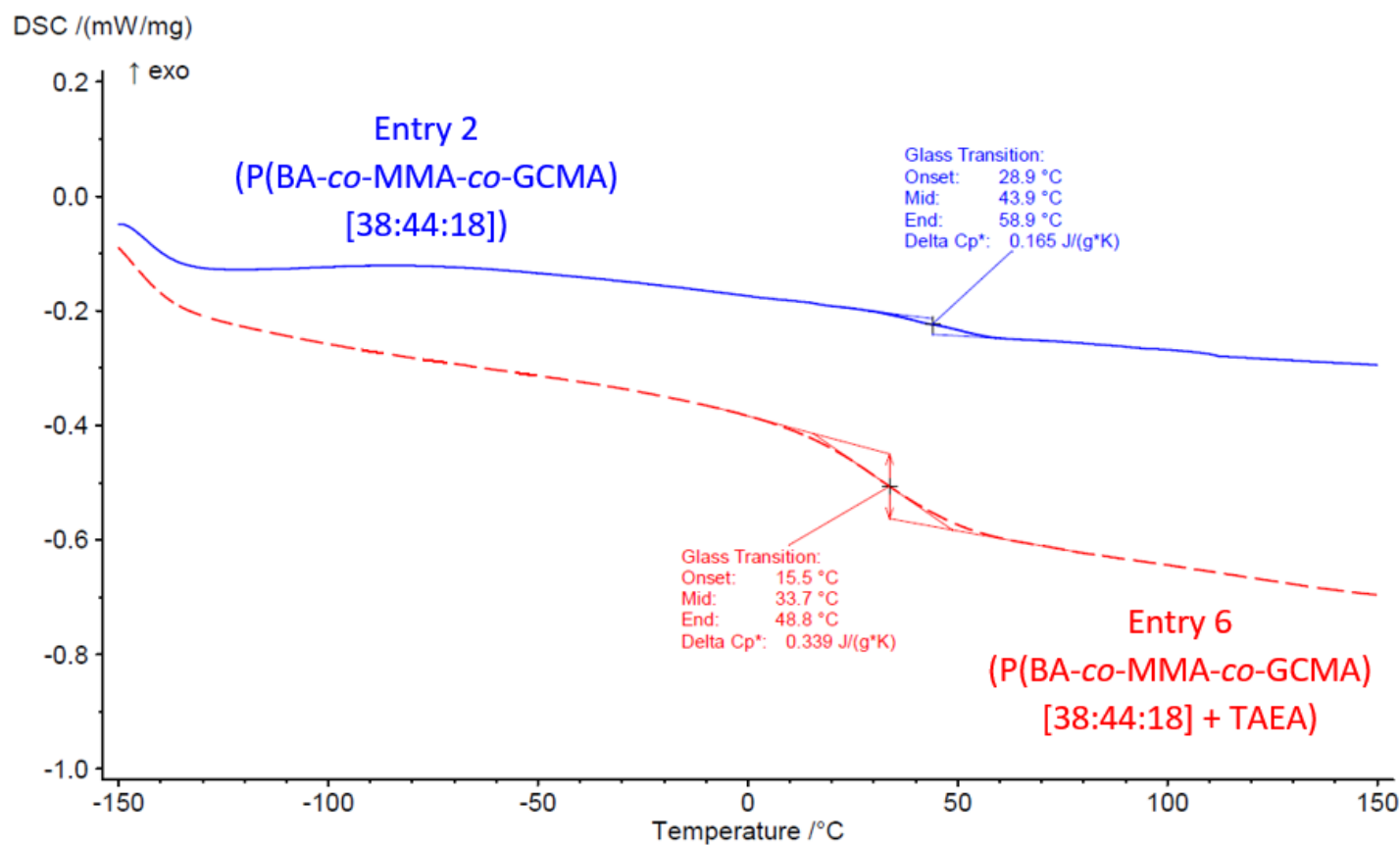

Figure 5. DSC thermograms of of entry 2 (P(BA-co-MMA-co-GCMA) [38:44:18]) and entry 6 (P(BA-co-MMA-coGCMA) [38:44:18] + TAEA).

Table 3. TGA, DSC, swelling index and gel content values of $P(B A-c o-M M A-c o-G C M A)$ copolymers cross-linked with TAEA.

\begin{tabular}{|l|c|c|c|c|c|c|}
\hline Entry & {$[\mathrm{BA}]:[\mathrm{MMA}]:[\mathrm{GCMA}]$} & $\mathrm{Td} 5 \%$ & $\begin{array}{c}\text { Char } \\
\text { yield }\end{array}$ & $\mathrm{T}_{\mathrm{g}}\left({ }^{\circ} \mathrm{C}\right)$ & $\mathrm{SI}(\%)$ & $\mathrm{GC}(\%)$ \\
\hline 5 & $47: 35: 18$ & 221 & 5.7 & 36 & 172 & 100 \\
\hline 6 & $38: 44: 18$ & 188 & 4.0 & 34 & 149 & 100 \\
\hline 7 & $31: 51: 18$ & 179 & 11.1 & 37 & 170 & 100 \\
\hline
\end{tabular}

Swelling indexes of entries 5 to 7 were measured immersing cured copolymer samples in THF for $24 \mathrm{~h}$ and comparing the weight before and after the immersion. The resulting values showed that swelling index was between 149\% (entry 6), and 170\% (entries 5 and 7). On the other hand, the high yields of the aminolysis reaction of P(BA-co-MMA-Co-GCMA) with TAEA showed by FTIR spectroscopy was confirmed by the gel content of the cured copolymers. Thus, the reaction of the cyclic carbonate with TAEA can be considered as quantitative.

Thermo-mechanical properties of the three cross-linked materials have been measured by DMA and the results are displayed in Table 4. The storage modulus $\left(E^{\prime}\right)$ and $\tan \delta$ as function of 
the temperature are displayed in Figures $\mathrm{A} 13$ and $\mathrm{A} 14$, respectively. The alpha-transition temperatures $(T \alpha)$ have been measured at the maximum of the $\tan \delta$ for each cross-linked copolymer. All the cross-linked copolymers have similar thermo-mechanical properties. The $T_{\alpha}$ values are rather higher than $\mathrm{T}_{\mathrm{g}}$ values obtained by DSC (between +33 to $+37^{\circ} \mathrm{C}$ ) which is generally the case. The relatively broad peaks of $\tan \delta$ for all materials suggest some heterogeneity along the polymer chains, probably because of the different reactivity ratios of the three monomers employed to synthesize the copolymer and cross-linking nodes therefrom. Glassy and rubbery storage modulus have been taken for all the samples at -50 and $130{ }^{\circ} \mathrm{C}$, respectively. The three cross-linked copolymers exhibited similar values and similar stiffness. Thus, the BA/MMA ratio does not affect significantly the thermo-mechanical properties.

Table 4. Thermo-mechanical properties of the cross-linked copolymers (entries 5 to 7 ) obtained by DMA.

\begin{tabular}{|c|c|c|c|c|}
\hline Entry & {$[\mathrm{BA}]:[\mathrm{MMA}]:[\mathrm{GCMA}]$} & $\begin{array}{c}\mathrm{E}^{\prime} \text { glassy at }-50^{\circ} \mathrm{C}\left(10^{9}\right. \\
\mathrm{Pa})\end{array}$ & $\begin{array}{c}\mathrm{E}^{\prime} \text { rubbery at } 130^{\circ} \mathrm{C}\left(10^{6}\right. \\
\mathrm{Pa})\end{array}$ & $\mathrm{T} \alpha\left({ }^{\circ} \mathrm{C}\right)$ \\
\hline 5 & $47: 35: 18$ & 2.29 & 1.32 & 72 \\
\hline 6 & $38: 44: 18$ & 2.30 & 1.58 & 67 \\
\hline 7 & $31: 51: 18$ & 1.79 & 1.15 & 74 \\
\hline
\end{tabular}

\section{3. $P(B A-c o-M M A-c o-G C M A)$ films on steel and glass}

Films of some of the cross-linked copolymers were performed on two different surfaces (steel and glass) to check their adhesion strength for coating applications. Additionally, a few films of the uncross-linked copolymers were also performed on the same surfaces in order to compare their adhesion to these surfaces and then to verify the influence of the cross-linking on the adhesion capacity. Adhesion tests were carried out owing to ASTM D3359 method (Tape Test). Thus, a $150 \pm 50 \mu \mathrm{m}$ layer of the selected copolymers were applied on steel and glass surface with a bar coater. The copolymers were previously solubilized in a small amount of MEK, resulting in a viscous solution. MEK was chosen because both copolymers and TAEA were soluble in this solvent, which is commonly used in the coating industry. The results of the adhesion tests are displayed in Table 5, and pictures of the results of the ASTM D3359 method (Tape Test) on steel and glass of entry 2 and 6 are shown in Figures A15 to A18. All the tested copolymers (both cross-linked and uncross-linked) exhibited a good adhesion on steel (entries $1,2,5$ and 6). However, the adhesion was significantly better on glass for cured copolymers (entries 5 and 6) compare to the uncross-linked ones (entries 1 and 2). Thus, the curing reaction of $\mathrm{P}$ (BA-co-MMA-co-GCMA) with TAEA increased considerably the adhesion of the films on glass. Hydrogen bonds may be formed between the amine groups of TAEA and the hydroxyl groups of the silica surface, leading to an enhanced adhesion of the material to the glass surfaces.

Table 5. Results of the adhesion tests (ASTM D3359).

\begin{tabular}{|l|c|c|c|}
\hline Entry & {$[\mathrm{BA}]:[\mathrm{MMA}]:[\mathrm{GCMA}]$} & ASTM D3359 on steel* & ASTM D3359 on glass* \\
\hline 1 & $47: 35: 18$ & 5 & 2 \\
\hline 2 & $38: 44: 18$ & 4 & 1 \\
\hline 5 & $47: 35: 18$ & 5 & 5 \\
\hline 6 & $38: 44: 18$ & 5 & 5 \\
\hline
\end{tabular}

* 5 = best adhesion; 0 = worst adhesion. 


\section{Conclusion}

Three new copolymers of BA, MMA and GCMA were successfully synthesized and characterized. The different BA/MMA ratios allowed to modulate some properties of the resulting copolymers, especially the $T_{\mathrm{g}}$ value which increased with the MMA content. The use of GCMA, a comonomer bearing a cyclic carbonate function, allowed the cross-linking reaction of the copolymers by aminolysis. This cross-linking reaction consisted in the reaction between the cyclic carbonate function and TAEA to form a hydroxyurethane linkages, avoiding the use of isocyanates. The curing reaction was quantitative for all the copolymers in the employed conditions and started even at room temperature without the use of any catalyst. The thermomechanical properties of all cross-linked copolymers were rather similar and apparently did not have a strong dependency on the BA/MMA ratio. The adhesion strength tests showed that both cross-linked and uncross-linked copolymers were appropriate for coating applications on steel surfaces. However, cross-linking reaction considerably increased the adhesion on glass, which was weak before the cross-linking reaction. Thus, given the thermal, mechanical and adhesion properties of these copolymers, as well as the ease of curing process, these materials are suitable for coatings applications on different surfaces such as steel or glass.

\section{Rerferences}

[1] S. Nameer, T. Deltin, P.E. Sundell, M. Johansson, Bio-based multifunctional fatty acid methyl esters as reactive diluents in coil coatings, Prog. Org. Coat., 136 (2019) 105227, https://doi.org/10.1016/j.porgcoat.2019.105277.

[2] A. Goldschmidt, H.-J. Streitberger, BASF Handbook on Basics of Coating Technology, 2nd ed., Vincentz Network, Hannover, 2007.

[3] G. Tillet, B. Boutevin, B. Ameduri, Chemical reactions of polymer crosslinking and postcrosslinking at room and medium temperature, Progress in Polymer Science, 36 (2011) 191217, https://doi.org/10.1016/i.progpolymsci.2010.08.003.

[4] I. González, J.M. Asua, J.R. Leiza, The role of methyl methacrylate on branching and gel formation in the emulsion copolymerization of BA/MMA, Polymer, 48 (2007) 2542-2547, https://doi.org/10.1016/i.polymer.2007.03.015.

[5] S. Paul, Surface coatings. Science and technology, Chemical Pub. Co. Inc.,New York, NY; None, 1985.

[6] A. Nebioglu, J. Leon, I. Khudyakov, Advances in the Chemistry of Melamine Acrylate Oligomers, 2019.

[7] G. Gündüz, Chemistry, Materials, and Properties of Surface Coatings: Traditional and Evolving Technologies, DEStech Publications, Inc, 2015.

[8] M. Decostanzi, J. Lomège, Y. Ecochard, A.-S. Mora, C. Negrell, S. Caillol, Fatty acid-based cross-linkable polymethacrylate coatings, Prog. Org. Coat., 124 (2018) 147-157, https://doi.org/10.1016/i.porgcoat.2018.08.001.

[9] G. Lligadas, J.C. Ronda, M. Galià, V. Cádiz, Plant Oils as Platform Chemicals for Polyurethane Synthesis: Current State-of-the-Art, Biomacromolecules, 11 (2010) 2825-2835, https://doi.org/10.1021/bm100839x.

[10] L. Poussard, J. Lazko, J. Mariage, J.M. Raquez, P. Dubois, Biobased waterborne polyurethanes for coating applications: How fully biobased polyols may improve the coating 
properties, Prog. Org. Coat., 97 (2016) 175-183,

https://doi.org/10.1016/j.porgcoat.2016.04.003.

[11] B. Türel Erbay, I.E. Serhatlı, Synthesis of bis[(4-hydroxyethoxy)phenyl]sulfone containing urethane acrylates and their applications, Prog. Org. Coat., 76 (2013) 1-10,

https://doi.org/10.1016/i.porgcoat.2012.07.010.

[12] X. Baur, W. Marek, J. Ammon, A.B. Czuppon, B. Marczynski, M. Raulf-Heimsoth, H.

Roemmelt, G. Fruhmann, Respiratory and other hazards of isocyanates, Int. Arch. Occup.

Environ. Health, 66 (1994) 141-152, https://doi.org/10.1007/BF00380772.

[13] B.D. Reh, J.M.E. Weber, A Summary of health hazard evaluations; issues related to occupational exposure to isocyanates, 1989 to 2002, (2004),

[14] Official Journal of the European Union, in, 2009.

[15] S.M. Arnold, M.A. Collins, C. Graham, A.T. Jolly, R.J. Parod, A. Poole, T. Schupp, R.N.

Shiotsuka, M.R. Woolhiser, Risk assessment for consumer exposure to toluene diisocyanate

(TDI) derived from polyurethane flexible foam, Regul. Toxicol. Pharmacol., 64 (2012) 504-515,

https://doi.org/10.1016/j.yrtph.2012.07.006.

[16] A.Z. Yu, R.A. Setien, J.M. Sahouani, J. Docken, D.C. Webster, Catalyzed non-isocyanate

polyurethane (NIPU) coatings from bio-based poly(cyclic carbonates), J. Coat. Technol. Res., 16

(2019) 41-57, https://doi.org/10.1007/s11998-018-0135-7.

[17] J. Guan, Y. Song, Y. Lin, X. Yin, M. Zuo, Y. Zhao, X. Tao, Q. Zheng, Progress in Study of NonIsocyanate Polyurethane, Ind. Eng. Chem. Res., 50 (2011) 6517-6527,

https://doi.org/10.1021/ie101995j.

[18] S.-H. Pyo, P. Persson, M.A. Mollaahmad, K. Sörensen, S. Lundmark, R. Hatti-Kaul, Cyclic carbonates as monomers for phosgene- and isocyanate-free polyurethanes and polycarbonates, 84 (2011) 637, https://doi.org/10.1351/PAC-CON-11-06-14.

[19] O. Kreye, H. Mutlu, M.A.R. Meier, Sustainable routes to polyurethane precursors, Green Chem., 15 (2013) 1431-1455, https://doi.org/10.1039/C3GC40440D.

[20] B. Nohra, L. Candy, J.-F. Blanco, C. Guerin, Y. Raoul, Z. Mouloungui, From Petrochemical Polyurethanes to Biobased Polyhydroxyurethanes, Macromolecules, 46 (2013) 3771-3792, https://doi.org/10.1021/ma400197c.

[21] L. Maisonneuve, O. Lamarzelle, E. Rix, E. Grau, H. Cramail, Isocyanate-Free Routes to Polyurethanes and Poly(hydroxy Urethane)s, Chem. Rev., 115 (2015) 12407-12439, https://doi.org/10.1021/acs.chemrev.5b00355.

[22] A. Cornille, R. Auvergne, O. Figovsky, B. Boutevin, S. Caillol, A perspective approach to sustainable routes for non-isocyanate polyurethanes, Eur. Polym. J., 87 (2017) 535-552, https://doi.org/10.1016/i.eurpolymj.2016.11.027.

[23] O.L. Figovsky, L.D. Shapovalov, Nonisocyanate polyurethanes for adhesives and coatings, in: First International IEEE Conference on Polymers and Adhesives in Microelectronics and Photonics. Incorporating POLY, PEP \& Adhesives in Electronics. Proceedings (Cat.

No.01TH8592), 2001, pp. 257-264.

[24] D.C. Webster, A.L. Crain, Synthesis and applications of cyclic carbonate functional polymers in thermosetting coatings, Prog. Org. Coat., 40 (2000) 275-282,

https://doi.org/10.1016/S0300-9440(00)00114-4.

[25] V.W. Fegley, S.P. Rowland, Resinous esters of acrylic acid and methacrylic acid, in: R.a.H. Co (Ed.), 1952.

[26] J.F. Cooper, L. Myri, Catalytic process for producing alkylene carbonates, in, Jefferson Chem Co Inc, 1956.

[27] P.P. McClellan, Catalytic process for producing alkylene carbonates, in, Jefferson Chem Co Inc, 1959.

[28] C. Carré, Y. Ecochard, S. Caillol, L. Avérous, From the Synthesis of Biobased Cyclic Carbonate to Polyhydroxyurethanes: A Promising Route towards Renewable Non-Isocyanate Polyurethanes, ChemSusChem, 12 (2019) 3410-3430, https://doi.org/10.1002/cssc.201900737. 
[29] F.J. C., Polymerizable esters of acrylic and methacrylic acid and polymers thereof, in: E.I.D.P.D.N.A. COMPANY (Ed.), 1961.

[30] P.M. Gallop, Copolymers and hydrogels: process and articles made thereof, in: S.U. LLC (Ed.), 1983.

[31] H.E. Katz, Preparation of soluble poly(carbonyldioxyglyceryl methacrylate), Macromolecules, 20 (1987) 2026-2027, https://doi.org/10.1021/ma00174a057.

[32] B. Akio, N. Takashi, M. Haruo, Carbonate Formation from Oxiranes and Carbon Dioxide Catalyzed by Organotin Halide-Tetraalkylphosphonium Halide Complexes, Bull. Chem. Soc. Jpn., 60 (1987) 1552-1554, https://doi.org/10.1246/bcsi.60.1552.

[33] S.-Y. Park, H.-Y. Park, H.-S. Lee, S.-W. Park, C.-S. Ha, D.-W. Park, Synthesis of poly[(2-oxo1,3-dioxolane-4-yl) methyl methacrylate-co-ethyl acrylate] by incorporation of carbon dioxide into epoxide polymer and the miscibility behavior of its blends with poly (methyl methacrylate) or poly(vinyl chloride), J. Polym. Sci. A Polym. Chem., 39 (2001) 1472-1480, https://doi.org/10.1002/pola.1124.

[34] V. Caló, A. Nacci, A. Monopoli, A. Fanizzi, Cyclic Carbonate Formation from Carbon Dioxide and Oxiranes in Tetrabutylammonium Halides as Solvents and Catalysts, Org. Lett., 4 (2002) 2561-2563, https://doi.org/10.1021/ol026189w.

[35] K. Kossev, N. Koseva, K. Troev, Calcium chloride as co-catalyst of onium halides in the cycloaddition of carbon dioxide to oxiranes, J. Mol. Catal. A Chem., 194 (2003) 29-37, https://doi.org/10.1016/S1381-1169(02)00513-7.

[36] D.-W. Park, B.-S. Yu, E.-S. Jeong, I. Kim, M.-I. Kim, K.-J. Oh, S.-W. Park, Comparative studies on the performance of immobilized quaternary ammonium salt catalysts for the addition of carbon dioxide to glycidyl methacrylate, Catal. Today, 98 (2004) 499-504, https://doi.org/10.1016/j.cattod.2004.09.003.

[37] M. Caspari, B. Schmitt, Production of (2-oxo-1,3-dioxolan-4-yl)-methyl methacrylate for use e.g. in adhesives or paint, comprises transesterification of methyl methacrylate with glycerol carbonate using a metal 1,3-diketonate catalyst, in: E.R. GmbH (Ed.), 2005. [38] T. Endo, K. Kakimoto, B. Ochiai, D. Nagai, Synthesis and Chemical Recycling of a Polycarbonate Obtained by Anionic Ring-Opening Polymerization of a Bifunctional Cyclic Carbonate, Macromolecules, 38 (2005) 8177-8182, https://doi.org/10.1021/ma050791v. [39] M. Yoshikawa, N. Hotta, J. Kyoumura, Y. Osagawa, T. Aoki, Chiral recognition sites from carbonyldioxyglyceryl moiety by an alternative molecular imprinting, Sens. Actuator B Chem., 104 (2005) 282-288, https://doi.org/10.1016/j.snb.2004.05.025.

[40] W.-L. Wong, K.-C. Cheung, P.-H. Chan, Z.-Y. Zhou, K.-H. Lee, K.-Y. Wong, A tricarbonyl rhenium(i) complex with a pendant pyrrolidinium moiety as a robust and recyclable catalyst for chemical fixation of carbon dioxide in ionic liquid, ChemComm, (2007) 2175-2177, 10.1039/B618423E.

[41] A. Westfechtel, Process for the preparation of glycerincarbonate esters, in: E.O. GmbH (Ed.), 2008.

[42] S. Jana, H. Yu, A. Parthiban, C.L.L. Chai, Controlled synthesis and functionalization of PEGylated methacrylates bearing cyclic carbonate pendant groups, J. Polym. Sci. A Polym. Chem., 48 (2010) 1622-1632, https://doi.org/10.1002/pola.23928.

[43] V. Besse, F. Camara, C. Voirin, R. Auvergne, S. Caillol, B. Boutevin, Synthesis and applications of unsaturated cyclocarbonates, Polym. Chem., 4 (2013) 4545-4561, 10.1039/C3PY00343D.

[44] F. Camara, S. Caillol, B. Boutevin, Free radical polymerization study of glycerin carbonate methacrylate for the synthesis of cyclic carbonate functionalized polymers, Eur. Polym. J., 61 (2014) 133-144, https://doi.org/10.1016/i.eurpolymj.2014.10.001.

[45] C. Decker, K. Moussa, A new class of highly reactive acrylic monomers, 1. Light-induced polymerization, Macromol. Rapid Commun., 11 (1990) 159-167,

https://doi.org/10.1002/marc.1990.030110404. 
[46] H. Kilambi, E.R. Beckel, J.W. Stansbur, C.N. Bowman, Kinetic studies of novel (meth)acrylic monomers, Polym. Prepr. (Am. Chem. Soc., Div. Polym. Chem.), 45 (2004) 73-74,

[47] H. Kilambi, S.K. Reddy, L. Schneidewind, J.W. Stansbury, C.N. Bowman, Copolymerization and dark polymerization studies for photopolymerization of novel acrylic monomers, Polymer, 48 (2007) 2014-2021, https://doi.org/10.1016/j.polymer.2007.02.006.

[48] H. Kilambi, J.W. Stansbury, C.N. Bowman, Enhanced reactivity of monovinyl acrylates characterized by secondary functionalities toward photopolymerization and Michael addition: Contribution of intramolecular effects, J. Polym. Sci. A Polym. Chem., 46 (2008) 3452-3458, https://doi.org/10.1002/pola.22660.

[49] K.A. Berchtold, J. Nie, J.W. Stansbury, C.N. Bowman, Reactivity of Monovinyl (Meth)acrylates Containing Cyclic Carbonates, Macromolecules, 41 (2008) 9035-9043, https://doi.org/10.1021/ma801644j.

[50] J.C. Fang, Polymerizable esters of acrylic and methacrylic acid and polymers thereof, in, Du Pont, 1961.

[51] K.D. Schneider, H.D. Naarmann, Polymers containing carbonate groups, in, Basf Ag, 1979. [52] N. Kihara, T. Endo, Synthesis and reaction of polymethacrylate bearing cyclic carbonate moieties in the side chain, Macromol. Chem. Phys., 193 (1992) 1481-1492, https://doi.org/10.1002/macp.1992.021930624.

[53] J.-C. Brosse, D. Couvret, S. Chevalier, J.-P. Senet, Monomères acryliques à fonction carbonate cyclique, 1. Synthèse et polymérisation, Macromol. Rapid Commun., 11 (1990) 123 128, https://doi.org/10.1002/marc.1990.030110303.

[54] R.M. Garipov, V.A. Sysoev, V.V. Mikheev, A.I. Zagidullin, R.Y. Deberdeev, V.I. Irzhak, A.A. Berlin, Reactivity of Cyclocarbonate Groups in Modified Epoxy-Amine Compositions, Dokl. Phys. Chem., 393 (2003) 289-292, https://doi.org/10.1023/B:DOPC.0000003463.07883.c9. [55] C.D. Diakoumakos, D.L. Kotzev, Non-Isocyanate-Based Polyurethanes Derived upon the Reaction of Amines with Cyclocarbonate Resins, Macromol. Symp., 216 (2004) 37-46, https://doi.org/10.1002/masy.200451205.

[56] F. Camara, S. Benyahya, V. Besse, G. Boutevin, R. Auvergne, B. Boutevin, S. Caillol, Reactivity of secondary amines for the synthesis of non-isocyanate polyurethanes, Eur. Polym. J., 55 (2014) 17-26, https://doi.org/10.1016/i.eurpolymj.2014.03.011.

[57] H. Tomita, F. Sanda, T. Endo, Model reaction for the synthesis of polyhydroxyurethanes from cyclic carbonates with amines: Substituent effect on the reactivity and selectivity of ringopening direction in the reaction of five-membered cyclic carbonates with amine, J. Polym. Sci. A Polym. Chem., 39 (2001) 3678-3685, https://doi.org/10.1002/pola.10009.

[58] A. Cornille, M. Blain, R. Auvergne, B. Andrioletti, B. Boutevin, S. Caillol, A study of cyclic carbonate aminolysis at room temperature: effect of cyclic carbonate structures and solvents on polyhydroxyurethane synthesis, Polym. Chem., 8 (2017) 592-604, 10.1039/C6PY01854H. [59] I. Javni, D.P. Hong, Z.S. Petrović, Soy-based polyurethanes by nonisocyanate route, J. Appl. Polym. Sci., 108 (2008) 3867-3875, https://doi.org/10.1002/app.27995.

[60] I. Javni, D.P. Hong, Z.S. Petrović, Polyurethanes from soybean oil, aromatic, and cycloaliphatic diamines by nonisocyanate route, J. Appl. Polym. Sci., 128 (2013) 566-571, https://doi.org/10.1002/app.38215.

[61] M. Bähr, A. Bitto, R. Mülhaupt, Cyclic limonene dicarbonate as a new monomer for nonisocyanate oligo- and polyurethanes (NIPU) based upon terpenes, Green Chem., 14 (2012) 1447-1454, 10.1039/c2gc35099h.

[62] M. Brym, C. Rösch, C. Haaf, A.M. Steinbrecher, H. Schäfer, O. Elizalde, Two-component coating compositions, in: B. SE (Ed.), 2012.

[63] B. Nohra, L. Candy, J.-F. Blanco, Y. Raoul, Z. Mouloungui, Synthesis of High-MolecularWeight Multifunctional Glycerol Polyhydroxyurethanes PHUs, Molecules, 21 (2016) 1220, https://doi.org/10.3390/molecules21091220. 
[64] S. Gennen, B. Grignard, J.M. Thomassin, B. Gilbert, B. Vertruyen, C. Jerome, C. Detrembleur, Polyhydroxyurethane hydrogels: Synthesis and characterizations, Eur. Polym. J., 84 (2016) 849-862, https://doi.org/10.1016/i.eurpolymj.2016.07.013.

[65] M.M. Mazurek-Budzyńska, G. Rokicki, M. Drzewicz, P.A. Guńka, J. Zachara, Bis(cyclic carbonate) based on d-mannitol, d-sorbitol and di(trimethylolpropane) in the synthesis of nonisocyanate poly(carbonate-urethane)s, Eur. Polym. J., 84 (2016) 799-811, https://doi.org/10.1016/j.eurpolymj.2016.04.021.

[66] D.J. Fortman, J.P. Brutman, M.A. Hillmyer, W.R. Dichtel, Structural effects on the reprocessability and stress relaxation of crosslinked polyhydroxyurethanes, J. Appl. Polym. Sci., 134 (2017) 44984, https://doi.org/10.1002/app.44984.

[67] X. Chen, L. Li, K. Jin, J.M. Torkelson, Reprocessable polyhydroxyurethane networks exhibiting full property recovery and concurrent associative and dissociative dynamic chemistry via transcarbamoylation and reversible cyclic carbonate aminolysis, Polym. Chem., 8 (2017) 6349-6355, 10.1039/C7PY01160A.

[68] M. Janvier, P.-H. Ducrot, F. Allais, Isocyanate-Free Synthesis and Characterization of Renewable Poly(hydroxy)urethanes from Syringaresinol, ACS Sustain. Chem. Eng., 5 (2017) 8648-8656, https://doi.org/10.1021/acssuschemeng.7b01271.

[69] S. Verma, M. Nazish, R.I. Kureshy, N.-u.H. Khan, Bi-functional heterogeneous iron complexes for catalytic conversion of epoxides to cyclic carbonates and their application in the synthesis of polyurethane, Sustain. Energy Fuels, 2 (2018) 1312-1322,

https://doi.org/10.1039/C8SE00016F.

[70] R. Pela, H.-G. Kinzelmann, J. Gacria-Miralles, T. Kamm, P. Seggewiss, O. Hartmann, U. Licht, V. Leonhardt, V. Mormul, K.-H. Schumacher, G. Boerzsoenyi, R. Klopsch, One component composition based on compounds with at least two exo-vinylene cyclic carbonate units, in: H.A.C. Kgaa (Ed.), 2018.

[71] A.M. Aerdts, A.L. German, G.P.M. van der Velden, Determination of the reactivity ratios, sequence distribution and stereoregularity of butyl acrylate-methyl methacrylate copolymers by means of proton and carbon-13 NMR, Magn. Reson. Chem., 32 (1994) S80-S88, https://doi.org/10.1002/mrc.1260321315.

[72] E.L. Madruga, M. Fernández-García, A kinetic study of free-radical copolymerization of butyl acrylate with methyl methacrylate in solution, Macromolecular Chemistry and Physics, 197 (1996) 3743-3755, https://doi.org/10.1002/macp.1996.021971120.

[73] S.G. Roos, A.H.E. Müller, K. Matyjaszewski, Copolymerization of n-Butyl Acrylate with Methyl Methacrylate and PMMA Macromonomers: Comparison of Reactivity Ratios in Conventional and Atom Transfer Radical Copolymerization, Macromolecules, 32 (1999) 83318335, https://doi.org/10.1021/ma9819337.

[74] V.K. Konaganti, G. Madras, Photocatalytic and Thermal Degradation of Poly(methyl methacrylate), Poly(butyl acrylate), and Their Copolymers, Ind. Eng. Chem. Res., 48 (2009) 1712-1718, https://doi.org/10.1021/ie801646y.

[75] M. Fernández-García, R. Cuervo-Rodriguez, E.L. Madruga, Glass transition temperatures of butyl acrylate-methyl methacrylate copolymers, J. Polym. Sci. B Polym. Phys., 37 (1999) 2512-2520, https://doi.org/10.1002/(sici)1099-0488(19990901)37:17<2512::Aidpolb22>3.0.Co;2-2.

[76] M. Szycher, Szycher's Handbook of Polyurethanes, Second Edition, Taylor \& Francis, 2012. [77] F. Magliozzi, A. Scali, G. Chollet, D. Montarnal, E. Grau, H. Cramail, Hydrolyzable Biobased Polyhydroxyurethane Networks with Shape Memory Behavior at Body Temperature, ACS Sustain. Chem. Eng., 8 (2020) 9125-9135, https://doi.org/10.1021/acssuschemeng.0c02610. [78] M. Adeel, B. Zhao, L. Li, S. Zheng, Nanocomposites of Poly(hydroxyurethane)s with Multiwalled Carbon Nanotubes: Synthesis, Shape Memory, and Reprocessing Properties, ACS Appl. Polym. Mater., 2 (2020) 1711-1721, https://doi.org/10.1021/acsapm.0c00183. 